
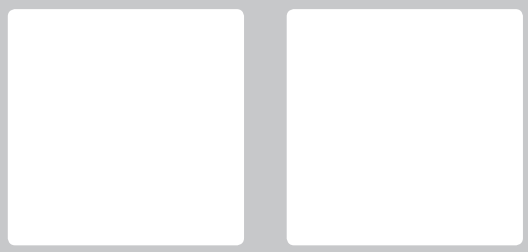

\title{
MAPEAMENTO DE NEGÓCIOS SOCIAIS E ORGANIZAÇÕES CONGÊNERES NO BRASIL
}

\section{Mapping of Social Business and Similar Organizations in Brazil}

\section{Caio Sousa Silva}

Mestrando em Administração de Empresas. Centro Univ. da FEl.

São Bernardo do Campo, SP. Brasil.e-mail:caiosousa.mx@hotmail.com

\section{Edson Sadao lizuka}

Doutor (2008) em Administração Pública e Governo. Professor do curso de Graduação em Administração e do Programa de Mestrado e Doutorado em Administração do Centro Universitário FEl.

São Bernardo do Campo, SP. Brasil.e-mail:esadao@fei.edu.br

\section{RESUMO}

Este estudo teve como objetivo desenvolver um mapeamento de negócios sociais no Brasil, para a criação de um banco de dados e, em seguida, analisar as empresas encontradas. Trata-se de uma pesquisa exploratória, na qual identificaram-se os atores deste campo que contribuem para a melhoria social. Após um levantamento sistemático, chegamos a 200 negócios sociais espalhados pelo Brasil, e 23 aceleradoras/investidoras. Os resultados indicam que essas empresas encontram-se num estágio inicial de negócios, e que $92 \%$ não possuem restrições para a distribuição de lucros. Em relação aos modelos de empresas, encontramos: 6 Empresas Cooperativas (3\%); 13 Empresas Base da Pirâmide (6,5\%); 17 Negócios Inclusivos (8,5\%); 3 Empresas do Modelo B Corp (1,5\%); e 161 Negócios Sociais (80,5\%). A literatura acadêmica indica a necessidade de pesquisas com mais casos e exemplos concretos de negócios sociais. Portanto, ter uma base de dados empírica auxiliará o desenvolvimento de novos artigos e teses sobre esta temática.

Palavras-chave: Negócios Sociais. Mapeamento. Empreendedorismo Social.

\section{ABSTRACT}

This study aimed to develop a mapping of social business in Brazil, in order to create a database and then analyze the companies found. It is an exploratory research, in which we identified the actors of this field that contribute to social improvement. After a systematic survey, we found 200 social business spread across Brazil and 23 accelerators/investors. Results indicate that these companies are at an early stage of business and $92 \%$ have no restrictions for the distribution of profits. Regarding the business models, there were: 6 Cooperative Companies (3\%); 13 'Base of the Pyramid' Companies (6.5\%); 17 Inclusive Business (8.5\%); 3 'Model B Corp' Companies (1.5\%); and 161 Social Business (80.5\%). Academic literature indicates the need to include more cases and concrete examples of social business in future research. Therefore, an empirical database will help the development of new articles and dissertations on the subject.

Keywords: Social Businesses. Mapping. Social Entrepreneurship. 


\section{INTRODUÇÃO}

As organizações são divididas entre os setores de empresas públicas (primeiro setor), de empresas privadas (segundo setor), e o terceiro setor, onde estão aquelas empresas caracterizadas como sociedade civil (associações e entidades sem fins lucrativos). Alguns fatores podem ser responsáveis por mudanças na classificação das empresas nesses setores, principalmente em relação ao papel que uma organização desempenha numa sociedade e na legislação em que ela se encaixa. Um exemplo é o surgimento dos negócios sociais ${ }^{1}$ (BUGG-LEVINE; KOGUT; KULATILAKA, 2012; YUNUS, 2009) empresas que incorporam diferentes características organizacionais do setor privado e da sociedade civil (BATTILANA et al., 2015).

Verifica-se que a tentativa de integrar os objetivos sociais e econômicos está na essência da criação dos NS; caracterizados como uma das vertentes do empreendedorismo social (LOARNE-LEMAIRE; MAALAOUI; DANA, 2017; KERLIN, 2012), essas empresas são criadas com o objetivo de resolver um problema social e/ou ambiental, utilizando mecanismos de mercado (DOBSON et al., 2018; GRASSL, 2012).

Comini, Barki e Aguiar (2012) analisaram os Negócios Sociais a partir de três perspectivas. Primeiro, pela perspectiva europeia, a qual apresenta os conflitos na busca entre os resultados lucrativos e os sociais, e mostra que os Negócios Sociais devem ser classificados como uma empresa que defende o caráter coletivo e associativo das organizações nesse campo de estudo. Por outro lado, a escola norte-americana crê que os Negócios Sociais se incluem na visão das empresas modelo B-Corp, e também das empresas na base da pirâmide, todas elas admitindo a distribuição de dinheiro aos sócios. E, finalmente, pela perspectiva dos países em desenvolvimento (emergentes), na qual os Negócios Sociais podem incluir uma parcela da população mais pobre e excluída.

O ganhador do Prêmio Nobel da Paz de 2006, Muhamad Yunus, entende que essas empresas devem ser criadas com uma missão social ou ambiental, e que os proprietários devem receber apenas o retorno do valor investido, deixando o lucro excedente para o crescimento da própria organização e da comunidade na qual ela está inserida (YUNUS, 2007).
Muito embora se reconheça que existe um debate em andamento neste tema, deve-se considerar, ao mesmo tempo, que se trata de um assunto que vem conquistando espaço na agenda de diversos pesquisadores (BOCKEN; FIL; PRABHU, 2016), e até mesmo de profissionais dedicados à criação de novas empresas, produtos ou serviços em distintos contextos e ambientes organizacionais. Além disso, parece haver uma busca por um caminho teórico mais sólido e robusto (SMITH; GONIN; BESHAROV, 2013). Outra corrente, representada por Stuart Hart e Michael $\mathrm{Chu}$, professores estudiosos do tema nas universidades Cornell e Harvard, defende a distribuição de lucros, por entender que isso possibilita atrair mais investidores e criar novos negócios na velocidade necessária para superar os desafios sociais existentes no mundo (IIZUKA et al, 2014).

Independentemente das linhas teóricas já estudadas sobre o tema, pesquisadores nacionais e internacionais são praticamente unânimes em apontar para a necessidade de pesquisas empíricas sobre os negócios sociais, com estudos de caso que contribuam para o avanço teórico (ROMANI-DIAS et al., 2017; TISCOSKI; ROSOLEN; COMINI, 2013).

Assim, este artigo teve como objetivo principal mapear os negócios sociais presentes no Brasil, assim como analisar suas características e atuação. $\mathrm{O}$ trabalho contribui para o avanço do conhecimento ao apresentar um banco de dados sistematizado sobre os negócios sociais, permitindo que pesquisadores e empreendedores tenham uma visão ampla de como as empresas atuam em nível nacional. O artigo também apresenta sugestões para pesquisas futuras, e possíveis relações dos negócios sociais com outros campos de estudo.

\section{REFERENCIAL TEÓRICO}

\subsection{Literatura sobre os negócios sociais}

Os negócios sociais representam o equilíbrio entre objetivos sociais e/ou ambientais e a geração de lucro (DOBSON et al., 2018); diferentemente das ONG's, eles possuem total autonomia financeira. Por outro lado, as empresas tradicionais têm como prin- 
cipal objetivo a maximização dos lucros dos sócios, ou seja, objetivos apenas financeiros (BARKI, 2015).

Umas das características que diferenciam os negócios sociais das organizações sem fins lucrativos é o fato de utilizarem métodos de mercado para a construção de suas formas de rentabilidade financeira, não focadas em ações filantrópicas/doações vindas de outras empresas. Outra diferença é a motivação para a criação dessas empresas, que já nascem com um objetivo claro em relação à comunidade, ao mercado e ao ambiente em que estão inseridas (BARKI, 2015).

Comini, Barki e Aguiar (2012) argumentam que, apesar de existirem empresas que se declaram como negócios sociais, o tema é relativamente novo e ainda com muitas informações e pesquisas a serem exploradas; assim, o conceito de negócios sociais como fenômeno organizacional não apresenta consenso entre os teóricos.

Pless (2012) apresenta de forma objetiva os empreendedores sociais, cuja intenção central é inovar e causar mudanças sociais; ou seja, tais empreendedores buscam soluções para problemas sociais que são, em geral, negligenciados pela sociedade.

Dacin, Dacin e Tracey (2011) buscam entender a teoria de Negócios Sociais a partir de esforços que tentaram identificar o surgimento do empreendedorismo social e compará-lo a outras atividades organizacionais, como o empreendedorismo convencional. Os autores mostram várias oportunidades de avanços em pesquisas relacionadas ao tema (empreendedorismo convencional, institucional e cultural), sendo que os pesquisadores de empreendedorismo social podem encontrar informações valiosas examinando lições desses tipos de empreendedorismo.

No entanto, como um campo emergente, há uma série de debates envolvendo a clareza das definições conceituais. Além disso, existem várias teorias simplificadas e genéricas sobre o tema, o que abre várias oportunidades de pesquisas relacionadas a Negócios Sociais (DACIN; DACIN; TRACEY, 2011).

Muhammad Yunus destacou o papel dos $\mathrm{Ne}$ gócios Sociais e seu potencial de expansão por meio da educação. Ele afirma que o objetivo da educação não é enriquecer as pessoas, mas enriquecer a vida por meio da ajuda ao próximo, e assim é possível reduzir a pobreza (KICKUL et al., 2012). Yunus foi o percursor das experiências do Grammen Bank, que é referência seminal em Negócios Sociais, pois foi o primeiro banco no mundo especializado em microcrédito, visando erradicar a pobreza. Com isso, apontou que os Negócios Sociais possuem um grande potencial de expansão mundial, na medida em que a pobreza existe em larga escala no mundo (YUNUS; MOINGEON; LEHMANN, 2012).

No que se refere ao conhecimento prático dos Negócios Sociais, pode-se destacar o estudo denominado "Mapeamento do Campo de Negócios Sociais/Negócios Inclusivos", de 2010, liderado pela empresa de pesquisa Plano CDE em parceria com a Fundação AVINA, a Potencia Ventures e a Aspen Network of Development Entrepreneurs (ANDE). Foram mapeados Negócios Sociais e Inclusivos em todo o país, bem como organizações que apoiam o seu desenvolvimento. Além disso, pode-se citar o levantamento denominado " 1 Mapa de Negócios de Impacto Social + Ambiental" desenvolvido pelo PIPE Social, em conjunto com a Vox Capital, e patrocinado pelo Itaú, Força Tarefa de Finanças Sociais e CiEB (Centro de Inovação para a Educação Brasileira), no ano de 2017, no qual foram localizadas 579 organizações. Nessa mesma linha, podemos citar o trabalho da Brasil Tomorrow, que começou na Europa em 2014, e no qual foram mapeadas mais de 2.500 iniciativas de inovação social; no Brasil, de acordo com dados de 2018, os organizadores mencionam 250 cadastros de iniciativas que promovem a inovação social. Diante disso, pode-se dizer que há exemplos concretos de levantamentos de negócios sociais e organizações congêneres; entretanto, não há uma base aberta $\mathrm{e}$ pública disponível para que pesquisadores avancem no conhecimento científico ou mesmo empírico do tema.

Em relação ao atual estado da arte, ao analisar as revisões sistemáticas e bibliométricas sobre o tema, verificou-se que é necessário aumentar as análises de caráter empírico, e também ampliar o número de experiências concretas conhecidas sobre negócios sociais (ROMANI-DIAS et al., 2017; DOHERTY; HAUGH; LYON, 2014; TISCOSKI; ROSOLEN; COMINI, 2014). Assim, esta pesquisa se justifica por realizar um mapeamento e analisar a atuação dos negócios sociais em nível nacional. 


\subsection{Definições de negócios sociais}

Os NS são organizações que buscam, ao mesmo tempo, resultados econômico-financeiros, impacto social e ambiental positivos, ou seja, não se trata de uma empresa tradicional com responsabilidade social, pois sua missão está ligada essencialmente à geração de alguma forma de impacto positivo na sociedade (WRY; YORK, 2017; JAHCHAN; COMINI; D'AMARIO, 2016).

O Quadro 1 apresenta a definição de algumas terminologias relacionadas aos negócios sociais:

Quadro 1 Termos relacionados aos negócios sociais

\begin{tabular}{l|l|l}
\multicolumn{1}{c|}{ Termo } & \multicolumn{1}{c|}{ Definição } & \multicolumn{1}{c}{ Principais Autores } \\
\hline Empresa Social & $\begin{array}{l}\text { É um negócio que visa, primariamente, a objetivos sociais, e cujos } \\
\text { excedentes são principalmente reinvestidos no próprio negócio } \\
\text { ou em benefícios para a comunidade. }\end{array}$ & $\begin{array}{l}\text { GUTIÉRREZ; REFICCO; TRUJILLO, 2006; } \\
\text { BORZAGA; DEPEDRI; GALERA, 2012 }\end{array}$ \\
\hline Negócios Sociais & $\begin{array}{l}\text { Qualquer tipo de empreendimento social que visa atender um } \\
\text { problema social. Tem como principal objetivo o impacto social e, } \\
\text { em seu modelo de negócio, todo lucro deve ser reinvestido. }\end{array}$ & $\begin{array}{l}\text { YUNUS; MOINGEON; LEHMANN, 2012; } \\
\text { BORZAGA; DEPEDRI; GALERA, 2012; }\end{array}$ \\
\hline Negócios Inclusivos & $\begin{array}{l}\text { Um Negócio Social pode ser considerado um negócio inclusivo } \\
\text { quando está focado em gerar emprego e renda para as pessoas } \\
\text { pobres que vivem em áreas de risco social e ambiental. }\end{array}$ & $\begin{array}{l}\text { TEODÓSIO; COMINI, 2012; GODÓl- } \\
\text {-DE-SOUSA; FISCHER, 2012; GOLJA; } \\
\text { POŽEGA, 2012 }\end{array}$ \\
\hline Negócios com Impacto Social & $\begin{array}{l}\text { Modelo de organização híbrida que combina as competências do } \\
\text { setor privado com os conhecimentos de gestão social do Terceiro } \\
\text { Setor. }\end{array}$ & BARKI, 2015 \\
\hline Negócios da Base da Pirâmide & $\begin{array}{l}\text { Modelo que ajuda a população de baixa renda a melhorar sua } \\
\text { qualidade de vida, fornecendo subsídios, principalmente, para } \\
\text { pessoas em vulnerabilidade social. }\end{array}$ & BARKI, 2010; PRAHALAD, 2005 \\
\hline Empresa B Corp & $\begin{array}{l}\text { Empresas com certificação do Sistema B são empresas com fins lu- } \\
\text { crativos certificadas pelo Laboratório B (organização internacional). }\end{array}$ & HONEYMAN, 2014 \\
\hline
\end{tabular}

Fonte Desenvolvido pelos Autores

O termo Empresa Social é frequentemente utilizado na Europa, e seu foco é a gestão compartilhada das empresas, visando apoio a órgãos do governo e organizações do terceiro setor, que também buscam atender as necessidades sociais da sociedade. Isto se deve à cultura dos países europeus, de criação de organizações como cooperativas e associações (BORZAGA; DEPEDRI; GALERA, 2012). As Empresas Sociais são negócios que visam, preferencialmente, os objetivos sociais da sociedade em que estão inseridas, e seus lucros excedentes são reinvestidos nas próprias empresas, com o objetivo de diminuir as desigualdades sociais e minimizar o impacto negativo que as organizações geram no meio ambiente (JÄGER; SCHRÖER, 2014).

Segundo Yunus; Moingeon e Lehmann (2012), um Negócio Social se caracteriza quando o lucro excedente retorna para o próprio negócio, na forma de melhores produtos e serviços, preços mais vanta- josos, entre outros princípios que beneficiam todos os envolvidos na organização. Isto é o contrário dos negócios que visam lucro, em que o excedente enriquece alguns poucos.

Para os autores, o conceito de Negócio Social vem despertando a curiosidade de muitos pesquisadores pelo mundo. Apesar da crescente literatura sobre o assunto, sua definição ainda está em debate. Yunus apresenta três fatores necessários para o Negócio Social: o modelo de receita empregado, produto/ serviço proposto para o cliente, e a forma como a empresa está organizada. No sistema capitalista tradicional, as empresas estão colocadas em dois lados: de um lado estão as organizações que buscam o crescimento dos lucros para os sócios. De outro estão as organizações sem fins lucrativos, que buscam maior interação social de uma comunidade (YUNUS; MOINGEON; LEHMANN, 2012). 


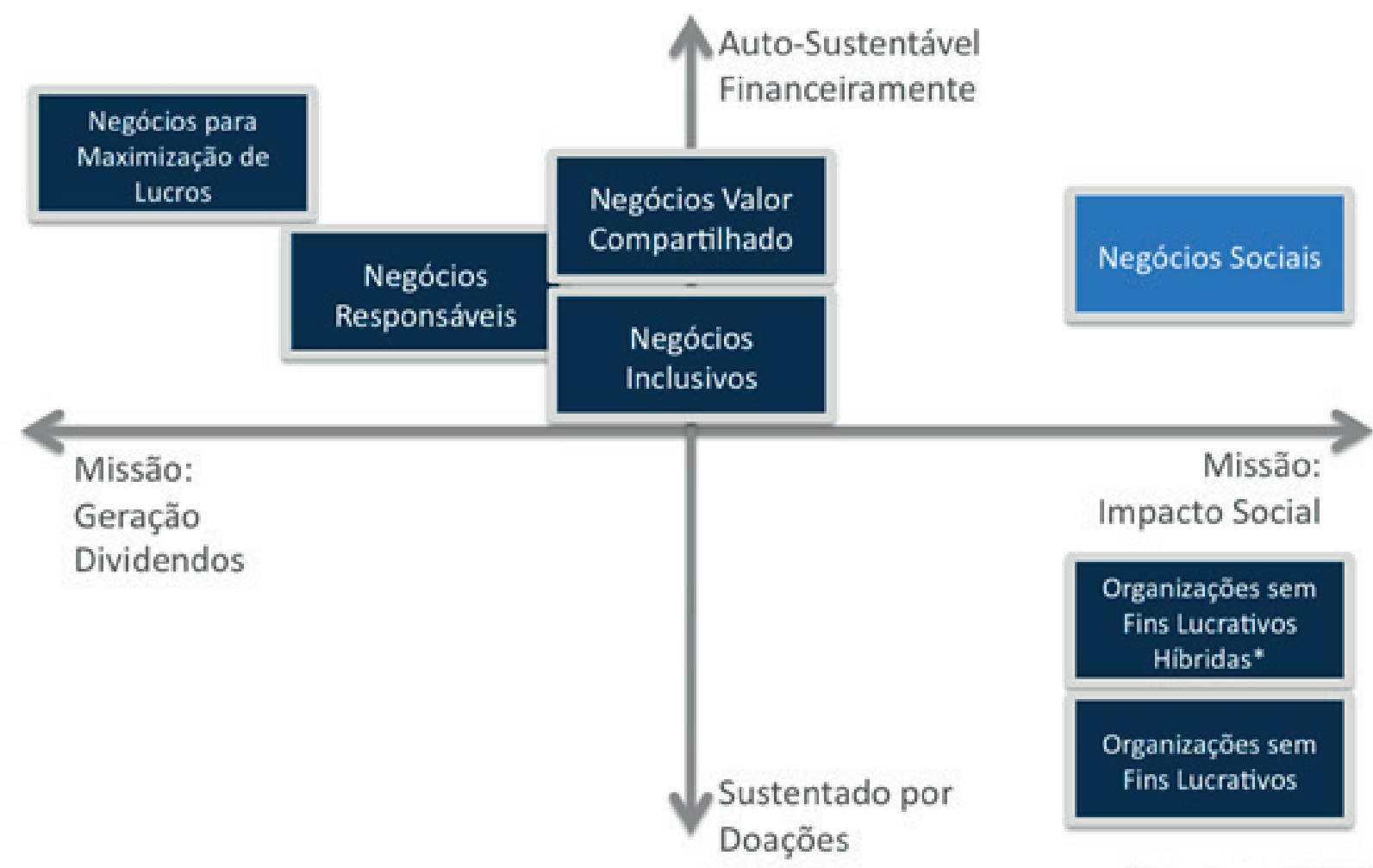

Figura 1 Modelos de negócios sociais

Fonte: Yunus (2012).

Outro tipo de organização é o Negócio Inclusivo, que mostra a importância da inclusão social das pessoas de baixa renda como atores, consumidores, fornecedores e distribuidores de produtos e serviços, e esta inclusão está focada na geração de negócios na base da pirâmide e/ou por pessoas que vivem em vulnerabilidade social e/ou ambiental (MÁRQUEZ; REFICCO; BERGER, 2009). Os Negócios Inclusivos têm como missão a ênfase em atividades econômicas que integrem os mais pobres na geração de cadeias valor, possibilitando que cada indivíduo seja respensável pela melhoria da sua condição de vida. No Brasil, o setor de Negócios Inclusivos está incorporado como um modelo de "valorização e desenvolvimento dos territórios, razão pela qual vem ganhando destaque crescente no conjunto das estratégias de atuação empreendidas tanto pelo setor público quanto privado" (SANTOS et al., 2010, p. 2).

É necessário avançar nos debates sobre Negócios Inclusivos para a construção de uma teoria mais consistente e profunda sobre a formação de negócios e combate à pobreza, bem como adequá-la a países emergentes como o Brasil. Esse tipo de negócio tem grande relevância como objeto de estudo acadêmico, podendo ser responsável pela construção de um espaço de transformação das atividades de combate à vulnerabilidade social, e constitui uma chance real de combater a pobreza intensa em diversas regiões do Brasil (BASTOS; VASCONCELLOS; TEODÓSIO, 2013).

Os negócios sociais são organizações cujo objetivo é a resolução de problemas sociais e/ou ambientais de uma sociedade, por meio de mecanismos empresariais; acima da maximização do lucro, elas possuemuma visão mais comunitária da realidade em que estão inseridas, buscando uma forma alternativa ao capitalismo tradicional (BARKI, 2015; THOMPSON; DOHERTY, 2006).

A combinação das características do setor privado com as competências administrativas do terceiro setor definem os NS. Eles são criados como soluções inovadoras para o desenvolvimento social, com geração de renda para a própria empresa e, ao mesmo tempo, incentivo ao fornecimento de produtos e serviços para diminuição da pobreza (BARKI, 2015). 
Prahalad (2005) retrata os negócios sociais como mais focados nas classes C, D e E, e afirma que a força que pode alterar o desenvolvimento econômico mundial está nas pessoas que vivem com até US\$ 2 por dia. Segundo o autor, essas pessoas são responsáveis por estabelecer e criar a estrutura da Base da Pirâmide, detalhada em seu livro "A Riqueza na Base da Pirâmide". Para estabelecer uma economia nesse modelo, é necessário mudar o gerenciamento de mercados tradicionais e compreender os desafios da sociedade e desses consumidores.

Na sua visão, é essencial estabelecer um modelo de aprendizagem para consumidores utilizarem produtos e serviços. O resultado esperado para essa estratégia é a mudança da pirâmide econômica, reduzindo o tamanho das classes de renda mais baixa e aumentando o tamanho da classe média; assim, seria possível buscar novas e criativas abordagens para converter a pobreza em oportunidade para todos.

Em seu Livro “The B Corp Handbook” (2014), Ryan Honeyman define as empresas B Corp como aquelas do setor privado que, de alguma forma, usam seus serviços e/ou produtos para o desenvolvimento da sociedade e do meio ambiente. O conceito das " $\mathrm{B}$ Corps" foi inserido pelo B-Lab nos Estados Unidos em 2006, com o objetivo de credenciar algumas empresas que geram impacto positivo na comunidade. Hoje, existem mais de 950 companhias - 75 delas na América Latina - em 30 países e 60 setores (HONEYMAN, 2014).

O principal objetivo do Sistema B é incentivar que as empresas sejam atores de mudança social na região onde estão inseridas, aumentando cada vez mais o número de organizações que querem transformar o mundo em um lugar melhor (HONEYMAN, 2014).

Polak e Warwick (2013) apresentam uma visão sobre o objetivo principal dos Negócios Sociais, na qual o lucro é o elemento principal para obter capital de investidores e fazer a empresa crescer. Para estes autores, os Negócios Sociais são negócios não convencionais, estruturados a partir de cooperação e de desenvolvimento sustentável. São baseados em características que se complementam e, uma vez juntas, trazem vantagem para as empresas e para sociedade.

Todos esses conceitos e tipos de negócios derivam do conceito de empreendedorismo social, ou seja, iniciativas sem fins lucrativos que têm como objetivo principal a produção de bens e serviços que, de alguma forma, beneficiem a sociedade, nas dimensões social, ambiental e econômica (LOARNE-LEMAIRE; MAALAOUI; DANA, 2017; DACIN; DACIN; TRACEY, 2011).

Assim, foram considerados diferentes conceitos para a montagem do banco de dados. Desde os chamados negócios sociais (que buscam equilíbrio entre o social e econômico), como também os negócios para a Base da Pirâmide (Prahalad), além dos negócios sociais que compartilham seus resultados com a comunidade (Yunus), as empresas B Corp (que são do setor privado e cujos serviços e/ou produtos atuam na sociedade e no meio ambiente), e os Negócios Inclusivos, que atuam diretamente sobre pessoas que vivem em vulnerabilidade social e/ou ambiental.

Em suma, $\mathrm{o}$ artigo busca apresentar as diferentes perspectivas teóricas relativas aos NS. Na medida em que são organizações emergentes no mercado brasileiro, considerou-se que, neste momento, esta seria a postura de pesquisa que poderia gerar mais benefícios aos estudiosos dedicados à temática dos negócios sociais.

\section{METODOLOGIA}

A pesquisa tem caráter exploratório, que é amplamente utilizado em tópicos que ainda estão em construção, como é o caso dos negócios sociais, principalmente no Brasil (SEVERINO, 2014). A localização de bancos de dados de empresas existentes no país foi a primeira etapa da pesquisa. Para a construção da base de dados inicial foi feito um levantamento com profissionais (Vox Capital, Potencia Ventures, Artemísia, Ashoka Brasil e Instituto de Cidadania Empresarial - ICE) e pesquisadores do campo dos NS (USP, USP-Leste, FGV-SP, FEI, ESPM, Mackenzie e Insper), para identificar as fontes de informação que poderiam ser interessantes para a pesquisa.

Depois desse esforço, chegou-se a três fontes de dados: Artemisia (organização sem fins lucrativos, pioneira na disseminação e no fomento de negócios sociais no Brasil); Projeto Brasil 27 (estudos de caso em todos os estados do país); e o Prêmio Empreendedor Social (principal concurso de empreendedo- 
rismo socioambiental na América Latina), como as principais fontes de informação sobre NS no Brasil.

A partir daí criou-se um banco de dados inicial, incorporando as empresas já citadas pelas três plataformas e suas experiências. Após esta etapa, iniciou-se a sistematização das empresas em planilha Excel. Os itens definidos para a sistematização foram de grande importância para os resultados empíricos da pesquisa, e enriquecem o banco de dados, uma vez que não existem informações detalhadas e compartilhadas sobre os negócios sociais no Brasil.

Buscou-se, então, identificar as fontes de dados mais eficientes para inclusão na sistematização. $\mathrm{O}$ Quadro 2 apresenta as cinco fontes de informação utilizadas na pesquisa para completar o banco de dados.

Quadro 2 Fonte de dados para a sistematização das empresas

\begin{tabular}{|c|c|c|}
\hline Categorias & Informações coletadas & Fontes de Referência \\
\hline $\begin{array}{l}\text { Descrição da Empresa } \\
\text { (Quem somos) }\end{array}$ & $\begin{array}{l}\text { Ramo de atuação } \\
\text { Tipo de Negócio } \\
\text { Posicionamento em relação à distribuição de lucros } \\
\text { Data de Abertura } \\
\text { O que faz a empresa } \\
\text { Público-Alvo }\end{array}$ & Site da Empresa; Blog;Facebook; Linkedin \\
\hline $\begin{array}{l}\text { Missão da Empresa } \\
\text { (Identidade) }\end{array}$ & $\begin{array}{l}\text { O que faz a empresa } \\
\text { Ramo de atuação } \\
\text { Tipo de Negócio }\end{array}$ & Site da Empresa; Blog;Facebook Linkedin \\
\hline Contate-nos & $\begin{array}{l}\text { Estado e Município } \\
\text { Número do CNPJ } \\
\text { E-mail e Telefone } \\
\text { Equipe }\end{array}$ & Site da Empresa; Blog;Facebook; Linkedin \\
\hline Cartão CNPJ & $\begin{array}{l}\text { Posicionamento em relação à distribuição de lucros } \\
\text { Natureza Jurídica } \\
\text { Verificar status da empresa (Ativa ou Inativa) } \\
\text { Data de Abertura } \\
\text { Estado e Município }\end{array}$ & Site da Receita Federal \\
\hline Reportagens e Notícias & $\begin{array}{l}\text { O que faz a empresa } \\
\text { Ramo de atuação } \\
\text { Tipo de Negócio }\end{array}$ & Endeavor; Universia; Sebrae. \\
\hline
\end{tabular}

Fonte: Desenvolvido pelos Autores

A pesquisa ocorreu em outubro de 2016, e priorizou buscar as informações na própria descrição e missão apresentadas no site institucional das empresas, partindo em seguida para o cadastro na Receita Federal (Cartão CNPJ). Quando não encontrada nenhuma informação, buscamos reportagens e artigos em três sites - Endeavor, Universia e Sebrae -, considerados relevantes devido à quantidade de tópicos publicados que abordam o empreendedorismo com impacto social. Muitos deles possuíam publicações citando empresas que já constavam da base inicial.

A segunda parte ocorreu em novembro de 2016, e foi caracterizada pela busca de informações complementares sobre Negócios Sociais. Ela não estava prevista no projeto inicial, e ocorreu por meio de questionários semiestruturados, enviados por correio eletrônico e mensagem na rede social oficial das empresas coletadas. Essa técnica se chama "Bola de Neve", e é um método usado para encontrar populações desconhecidas, que não foram identificadas em determinados temas (FREITAS et al., 2000). O passo inicial dessa técnica foi determinar atores e público-alvo envolvidos no objetivo do estudo, no caso os negócios sociais encontrados anteriormente. Esses elementos são chamados de onda zero ou sementes, que significa que serão a base inicial da busca.

A partir daí a Plataforma do Google Forms foi eleita para a criação do questionário enviado às empresas. O Google Forms é um aplicativo inovador para a construção de um formulário online, e pode 
ser disponibilizado por meio de um endereço eletrônico (MATHIAS; SAKAI, 2013). Foram criadas cinco questões relacionadas ao conhecimento das empresas sobre outros negócios, e a algumas características que consideram importantes para um NS.

Todas as empresas identificadas tiveram a mesma oportunidade de resposta ao questionário, e todos os empresários que contribuíram para o desenvolvimento da pesquisa terão acesso a este estudo detalhado, pelo compartilhamento dos resultados obtidos. Essa técnica também é prevista no método "Bola de Neve", para aperfeiçoar os resultados atingidos (FREITAS et al., 2000). Após determinar os atores, foram enviados questionários semiestruturados para as 181 empresas encontradas, em dezembro de 2016, utilizando as ferramentas de correio eletrônico e caixa de mensagem da rede social oficial (Facebook).

Obtivemos 28 respostas de 181 mensagens enviadas, e $85,7 \%$ dos empresários indicaram outras empresas de seu conhecimento, o que foi essencial para atingir os negócios sociais incluídos nesse estudo.

Gráfico 1 Empresas que indicaram outros negócios sociais

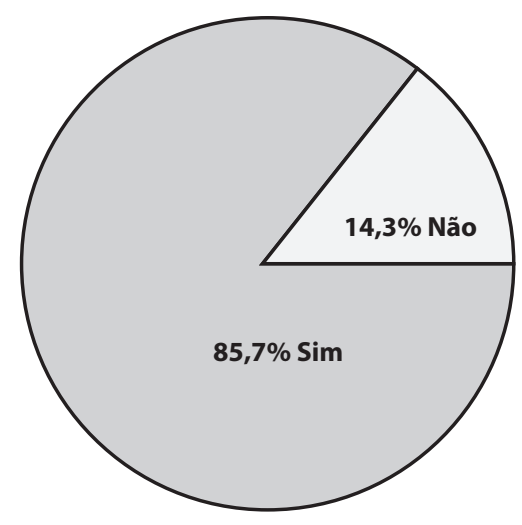

Fonte: Desenvolvido pelo Autores

Essa técnica possibilitou adicionar 28 empresas, por meio de indicação na base, chegando a 209 empresas no banco de dados. Após uma nova verificação dos NS localizados em fevereiro de 2016, identificou-se que nove dessas empresas haviam encerrado suas atividades ou as informações inicialmente obtidas não estavam acessíveis; portanto, não foram consideradas no estudo. Por fim, verificou-se que 200 negócios sociais eram passíveis de análise, e foram considerados na composição do banco de dados proposto.

\section{ANÁLISE DOS RESULTADOS}

Considerando os critérios adotados, encontraram-se 200 negócios sociais e 23 empresas ${ }^{2}$ investidoras/aceleradoras viáveis para a pesquisa. A Figura 2 apresenta o mapeamento total dos negócios sociais e investidores no Brasil, por região:

Figura 2 Mapeamento de empresas por região

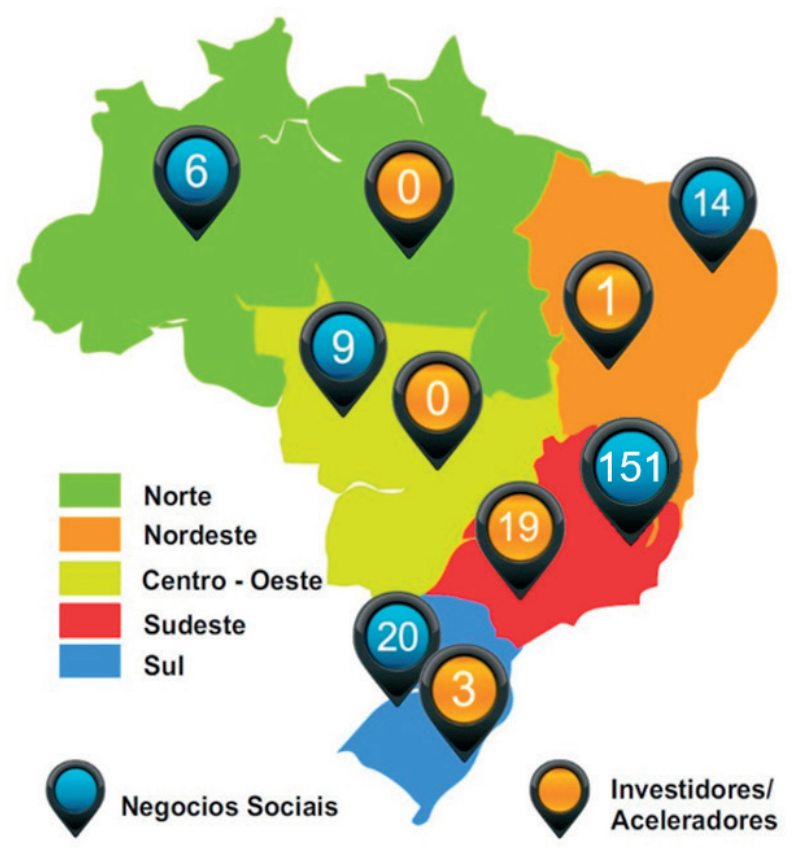

Fonte: Desenvolvido pelos Autores

O resultado é coerente com o esperado, com relação às regiões do Brasil em que as empresas estão sediadas (Centro-Oeste, Norte, Nordeste, Sudeste e Sul). Há uma predominância na região Sudeste $(75,5 \%)$, principalmente na cidade de São Paulo, resultado já esperado por ser esta a cidade mais desenvolvida do país e com o maior PIB, de R \$ 494,9 bilhões (SEADE, 2015).

Em relação aos modelos de negócios, encontramos as seguintes categorias:

Cooperativas - Foram encontradas seis empresas classificadas como cooperativas, conforme os critérios propostos. Um exemplo é a Coohabras,

2 A lista de empresas analisadas encontra-se no final do trabalho, no link

http://www.ice.org.br/premioice/2016/wp-content/uploads/2017/04/mencao-honrosa-graduacao-tcc.pdf 
empresa sediada em São Paulo, SP, que tem como objetivo ajudar pessoas de baixa renda a conquistar o sonho da casa própria. Para isso, a empresa desenvolveu um método de organização social, educação popular e poupança coletiva.

Base da Pirâmide - Em relação às empresas da Base da Pirâmide (Prahalad), foram encontradas 13 empresas. Um exemplo é a 4You2, empresa sediada em São Paulo, SP, que tem como objetivo fornecer cursos de idiomas a preços acessíveis e voltados às Classes C, D e E.

Negócios Inclusivos - 17 negócios inclusivos foram encontrados na pesquisa, e uma das empresas é a Hand Talk, sediada em Maceió, AL, especializada em Tecnologia Assistiva, e que realiza tradução digital e automática para Língua de Sinais, utilizada pela comunidade surda. A solução oferece ferramentas complementares ao trabalho do intérprete, para auxiliar a comunicação entre surdos e ouvintes.

Empresas do Modelo B Corp - Apenas três empresas foram classificadas como parte do Sistema B Corp. Um exemplo é a Avante, empresa sediada em São Paulo, SP, que tem como objetivo orientar seus clientes em produtos financeiros, recomendando os mais adequados para a sua vida, desde um cartão pré-pago até um consórcio, crédito consignado, financiamento ou seguro.

Negócios Sociais - Em relação aos negócios sociais que não se encaixam em outro modelo de negócio, foram encontradas 161 empresas, e elas representam a maior parte da amostra deste estudo. Um exemplo é a Treebos, empresa sediada em Guarapari, ES, que é um crowdfunding aplicado à agricultura sustentável.

Em relação à forma de distribuição de lucros, identificou-se que a grande maioria (184 empresas) adota retorno financeiro e distribuição de dividendos para seus investidores, ou seja, 3\% das empresas analisadas são cooperativas, $4,5 \%$ restringem a distribuição do lucro para os sócios, e $92,5 \%$ não possuem restrição na distribuição. Esse resultado indica que, no Brasil, a criação de negócios sociais tem um modelo diferente do proposto por Yunus, que defende que o investidor deve receber apenas o retorno de seu investimento, e nenhum lucro a mais.
Gráfico 2 Quantidade de negócios sociais criados por ano

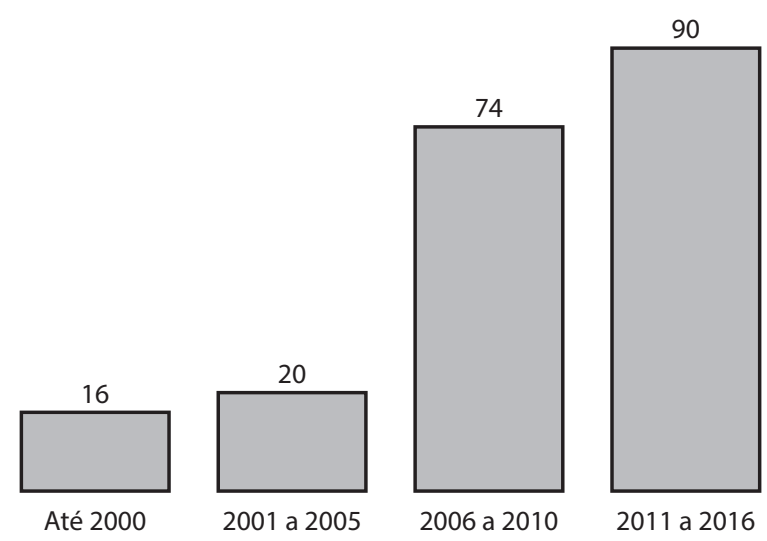

Fonte: Desenvolvido pelos Autores

Em relação à fundação de negócios sociais, os resultados mostram que a criação dessas empresas aumentou a partir de 2006, e $45 \%$ das empresas encontradas neste estudo foram fundadas entre $2011 \mathrm{e}$ 2016. Boa parte dos negócios sociais no país configuram-se como startups, ou seja, trata-se, possivelmente, de fenômeno recente e em crescimento. Os NS apresentam-se como diferentes modelos de empresas em relação ao padrão capitalista tradicional, que visa apenas o lucro para os acionistas, e nos últimos dez anos podem ser considerados frequentes como alternativas inovadoras na economia nacional. O gráfico 2 apresenta a quantidade de empresas fundadas em cada período, e as porcentagens em relação ao total encontrado neste estudo.

$\mathrm{Na}$ análise do ramo de atividades dos negócios sociais, foram analisadas 10 categorias diferentes, sendo as três mais frequentes: Sustentabilidade; Educação e Saúde, com 29,5\%, 18,5\% e 12,0\%, respectivamente. Pode-se considerar que essas três categorias são as mais comuns em empresas com o objetivo de NS, que visam combater a desigualdade ambiental/ social numa sociedade. Além disso, tal informação parece indicar que a maioria das organizações localizadas tem atuado, provavelmente, no equilíbrio entre os impactos sociais, ambientais e financeiros.

Por outro lado, outras três categorias importantes, menos frequentes, também aparecem: Inclusão Digital, Habitação e Consultoria, com 2,0\%, 2,5\% e $4,5 \%$, respectivamente. Isso pode representar um avanço nos modelos utilizados pelos negócios sociais, e a incorporação de novas tecnologias e métodos de atuação dessas empresas, apontando uma provável 
tendência de atuação e configuração desse tipo de negócio no Brasil. A Tabela 1 apresenta a quantidade de respostas para cada categoria.

Tabela 1 Ramo de atuação dos negócios sociais

\begin{tabular}{l|c|c}
\multicolumn{1}{c|}{ Ramo de Atuação } & \multicolumn{2}{c}{ Quantidade \% } \\
\hline Sustentabilidade & 59 & $29,50 \%$ \\
\hline Educação & 37 & $18,50 \%$ \\
\hline Saúde & 24 & $12,00 \%$ \\
\hline Empregabilidade & 17 & $8,50 \%$ \\
\hline Serviços Financeiros & 17 & $8,50 \%$ \\
\hline Plataforma virtual & 16 & $8,00 \%$ \\
\hline Tecnologia Assistiva & 12 & $6,00 \%$ \\
\hline Consultoria & 9 & $4,50 \%$ \\
\hline Habitação & 5 & $2,50 \%$ \\
\hline Inclusão Digital & 4 & $2,00 \%$ \\
\hline Total & $\mathbf{2 0 0}$ & $\mathbf{1 0 0} \%$ \\
\hline
\end{tabular}

Fonte: Desenvolvido pelos Autores

Dentro das categorias dos ramos de atuação, identificaram-se as atividades mais frequentes realizadas pelas empresas, que foram classificadas em quatro grupos distintos: Utilização de Plataformas, Sites e Portais Interativos; Utilização de aplicativo mobile; Desenvolvimento de novos produtos; e Atendimento especializado (pessoas de baixa renda).

O Quadro 3 o apresenta os ramos de atuação que estão presentes nessas atividades e alguns exemplos de empresas atuantes.

Em relação às atividades mais frequentes realizadas pelos empresários, identificou-se que os ramos Saúde e Educação são os únicos que estão presentes nos quatro grupos. As informações da base de dados dos NS indicaram que o uso das novas tecnologias de informação e comunicação, as chamadas TICs, estão em $22 \%$ do total de empresas, e também o desenvolvimento de produtos/serviços inovadores, com $16,5 \%$. O resultado mostra que os dois grupos estão presentes em boa parte dos NS brasileiros. Além disso, notou-se que $9 \%$ possuem um atendimento especializado para pessoas de baixa renda, ou seja, a base da pirâmide. E, finalmente, um quarto grupo de aplicativos aparece com 4,5\%.
Quadro 3 Atividades mais frequentes dos ramos de atuação dos NS

\begin{tabular}{l|l}
\hline \multicolumn{1}{c|}{ Atividade } & \multicolumn{1}{c}{\begin{tabular}{c}
\multicolumn{1}{c}{ Exemplos de Empresas/ } \\
Ramos de atuação
\end{tabular}} \\
\hline $\begin{array}{l}\text { 1. Utilização de } \\
\text { Plataformas, Sites e } \\
\text { Portais Interativos } \\
\text { (22,0\%) }\end{array}$ & $\begin{array}{l}\text { Bondetrampo (Empregabilidade) } \\
\text { Backpacker (Educação) } \\
\text { Vai voando (Plataforma Virtual) } \\
\text { Saútil (Saúde) } \\
\text { Catarse (Serviços Financeiros) } \\
\text { 100 Pepinos (Sustentabilidade) }\end{array}$ \\
\hline $\begin{array}{l}\text { 2. Desenvolvimento } \\
\text { de novos produtos } \\
\text { (16,5\%) }\end{array}$ & $\begin{array}{l}\text { Kapa+EcoProdutos (Empregabilidade) } \\
\text { IES2 (Educação) } \\
\text { Pratic (Saúde) } \\
\text { Urban 3D (Sustentabilidade) } \\
\text { The Products (Tecnologia Assistiva) }\end{array}$ \\
\hline $\begin{array}{l}\text { 3. Atendimento } \\
\text { especializado (Pessoas } \\
\text { de baixa renda) (9\%) }\end{array}$ & $\begin{array}{l}\text { Plano CDE (Consultoria) } \\
\text { Tekoha (Empregabilidade) } \\
\text { 4You2 (Educação) } \\
\text { Dr. Consulta (Saúde) } \\
\text { Artesol (Sustentabilidade) } \\
\text { Banco Pérola (Serviços Financeiros) }\end{array}$ \\
\hline $\begin{array}{l}\text { Monster Joy (Educação) } \\
\text { aplicativo mobile } \\
\text { (4,5\%) }\end{array}$ & $\begin{array}{l}\text { Eruga (Inclusão Digital) } \\
\text { Colab (Plataforma Virtual) } \\
\text { Positive Drop (Saúde) } \\
\text { Timokids (Tecnologia Assistiva) }\end{array}$ \\
\hline
\end{tabular}

Fonte: Desenvolvido pelos Autores

Para compreender a tese de mudança dessas organizações, ou seja, o impacto por elas pretendido, trabalhou-se com a análise de conteúdo (MOZZATO; GRZYBOVSKI, 2011; BARDIN, 2009), referente ao propósito dos negócios sociais que estavam descritos na missão, nos objetivos e em suas atividades. Em síntese, a tese de mudança das organizações analisadas pode ser vista na Figura 3.

Figura 3 Termos mais citados sobre a missão e objetivos dos NS

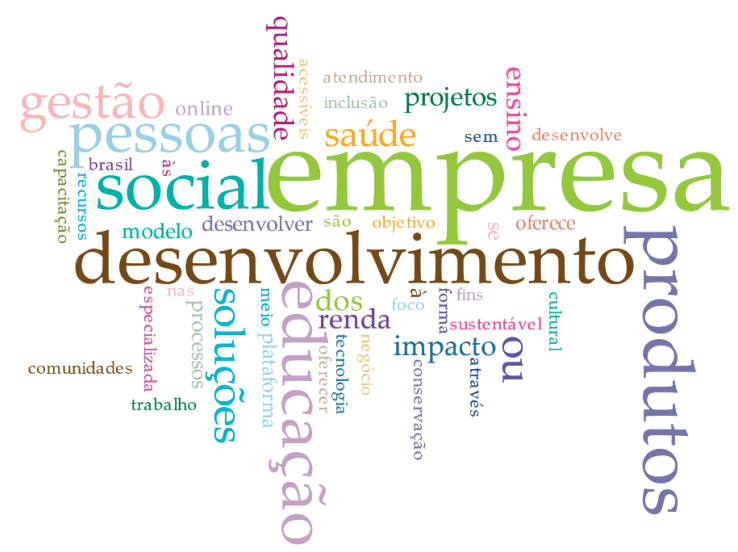

Fonte: Análise de conteúdo da missão, objetivos e propósito, a partir do software Voyant Tools 
Diante dos termos mais citados pelos negócios sociais, é possível compreender que tais organizações possuem como tese de mudança a atuação por meio de empresas com ação social, a partir de pessoas e gestão, buscando oferecer produtos que promovam o desenvolvimento. Isso parece indicar que tais organizações visam, de fato, gerar impacto social, econômico e, em alguns casos, ambiental positivo a partir de suas atividades.

Em relação às atividades mais realizadas pelos empresários, foram identificadas três com maior nú- mero de respostas, sendo a mais frequente o "Contato com Investidores e Aceleradoras", e, em seguida, a "Assessoria Profissional de Marketing", com a mesma frequência de "Planejamento Estratégico e Posicionamento de Mercado".

Essas três atividades foram identificadas como as mais requisitadas pelos proprietários de negócios sociais, e demonstram o quanto esses empresários querem e necessitam de apoio e investimento para o seu crescimento no mercado nacional.

Quadro 4 Exemplos de investidores/aceleradores de negócios sociais no Brasil

\begin{tabular}{l|l}
\multicolumn{1}{c|}{ Empresa } & \multicolumn{1}{c}{ Descrição } \\
\hline $\begin{array}{l}\text { Artemisia Negócios Sociais } \\
\text { (Aceleradora) }\end{array}$ & $\begin{array}{l}\text { A Artemisia é uma organização sem fins lucrativos, pioneira na disseminação e no fomento de negócios sociais } \\
\text { no Brasil. }\end{array}$ \\
\hline $\begin{array}{l}\text { Yunus Negócios Sociais } \\
\text { (Aceleradora) }\end{array}$ & $\begin{array}{l}\text { A Yunus Negócios Sociais Brasil tem como objetivo desenvolver Negócios Sociais pelo país, por meio de seu } \\
\text { fundo de investimentos e aceleradora para Negócios Sociais. }\end{array}$ \\
\hline $\begin{array}{l}\text { Vox Capital } \\
\text { (Investidora) }\end{array}$ & $\begin{array}{l}\text { A Vox Capital é uma empresa de capital empreendedor, que investe em negócios inovadores e de alto impacto, } \\
\text { que servem à população de baixa renda brasileira com soluções que ajudam a melhorar suas vidas. }\end{array}$ \\
\hline $\begin{array}{l}\text { Instituto Quintessa } \\
\text { (Aceleradora) }\end{array}$ & $\begin{array}{l}\text { O Instituto Quintessa é uma aceleradora de Negócios Sociais que, mediante o apoio às lideranças das organiza- } \\
\text { ções, visa consolidar e expandir os negócios no Brasil. }\end{array}$ \\
\hline $\begin{array}{l}\text { GIFE } \\
\text { (Investidora) }\end{array}$ & $\begin{array}{l}\text { O GIFE é uma organização sem fins lucrativos, que reúne os principais investidores do país, sendo eles de } \\
\text { origem empresarial, familiar, independente ou comunitária. }\end{array}$ \\
\hline $\begin{array}{l}\text { Gera Venture Capital } \\
\text { (Investidora) }\end{array}$ & $\begin{array}{l}\text { Gera é uma empresa de investimentos focada em educação no Brasil. Investe em empreendedores de alto } \\
\text { potencial para desenvolver seus negócios. }\end{array}$ \\
\hline
\end{tabular}

Fonte: Desenvolvido pelos Autores

O Quadro 4 apresenta alguns exemplos de investidores e aceleradores da pesquisa, dedicados aos negócios sociais. Essas empresas são responsáveis pelo crescimento de muitos negócios de sucesso, e buscam organizações que fogem do modelo de negócio convencional para adotar o modelo de NS. Por sua vez, muitas dessas aceleradoras são empresas sem finalidade lucrativa e oferecem apoio, como capital, tecnologia e treinamento gerencial, e reconhecimento da marca perante os clientes e parceiros, entre outros tipos

O tema dos negócios sociais ainda é objeto de debate entre os vários autores, porém os resultados deste estudo mostram sua capacidade de desenvolvimento para a sociedade brasileira, com o passar dos anos. Outro ponto relevante do estudo foi a metodologia de "Bola de Neve", utilizada para localizar negócios não encontrados inicialmente, por meio dos próprios empresários que receberam os questionários. Isso demonstrou que os empreendedores apoiam a iniciativa de que os negócios sociais devem trabalhar em sintonia para o desenvolvimento desse tipo de negócio.

A partir dos dados obtidos, verificou-se que, cada vez mais, pessoas e empresários estão interessados e empenhados em empreender de uma forma alternativa; como consequência, o modelo de NS tem um grande potencial de desenvolvimento no Brasil.

\section{CONCLUSÃO E IMPLICAÇÕES}

Tendo em vista que o tema dos negócios sociais está em crescimento em âmbito nacional e internacional, acreditamos que a pesquisa atingiu o objetivo geral proposto - desenvolver um mapeamento de 
negócios sociais no Brasil para a criação de um banco de dados.. De acordo com os resultados alcançados, pode-se dizer que a investigação proposta também cumpriu os objetivos específicos.

Considerando a metodologia adotada, os resultados constituem um avanço, no sentido de disponibilizar mais informações sobre os NS e de incluir mais organizações neste campo de atuação, visto que o crescimento deste tipo de negócio aumentou a partir do ano de 2011, ou seja, uma parcela dessas empresas ainda se encontra na fase inicial de negócio, como startups. Esta pesquisa não se limitou a mapear as empresas e cruzar os bancos de dados existentes, mas foi além, principalmente com a metodologia "Bola de Neve”, para encontrar mais negócios espalhados pelo Brasil.

$\mathrm{Na}$ análise das informações complementares sobre os NS, as três atividades consideradas mais relevantes pelos empresários foram: o "Contato com Investidores e Aceleradoras", e em seguida a "Assessoria Profissional de Marketing", com a mesma frequência de "Planejamento Estratégico e Posicionamento de Mercado". Esse resultado mostra o interesse por parte dos empreendedores em se relacionar com empresas investidoras e aceleradoras. No estudo foram encontradas 23 empresas que apoiam os negócios sociais.

Em relação aos tipos de negócios encontrados nas 200 empresas identificadas, estes foram classificados em cinco modelos: Cooperativas (3\%); Base da Pirâmide (6,5\%); Negócios Inclusivos (8,5\%); Empresas do Modelo B Corp (1,5\%); e Negócios Sociais (80,5\%). Esse resultado apresenta as tendências das empresas criadas no Brasil, no que se refere a NS, sendo que a grande maioria está concentrada na região Sudeste, especificamente, $75,5 \%$ do total.

Outro ponto relevante é a distribuição de dividendos dessas empresas. Em 92\% dos negócios, não existe restrição à distribuição de lucros entre os sócios. Esse resultado indica que há necessidade de promover mais conexões entre empreendedores; investidores e aceleradoras, com o objetivo de disseminar as alternativas de modelos de negócio que podem ser criados. Os NS baseados no modelo de Yunus ainda são em menor número no país, mas é possível que tal modelo se expanda ao longo dos anos.

Entre as informações captadas no estudo, uma delas indica o ramo de atuação dos NS brasileiros:
$29,5 \%$ atuam com sustentabilidade, e 18,5\% trabalham com educação; esses dois tipos de NS se destacaram no total de 10 ramos de atuação. Em relação às atividades mais frequentes realizadas pelas empresas, destacam-se a utilização de plataformas, sites, portais interativos e o desenvolvimento de novos produtos.

Este resultado parece indicar que o propósito dos negócios sociais brasileiros se relaciona com o desenvolvimento tecnológico, e de fato, à missão de desenvolvimento econômico, social e ambiental do país, reforçando a análise apresentada sobre a tese de mudança dessas organizações.

É importante apontar uma limitação encontrada na sistematização das empresas no banco de dados. Aproximadamente 32\% das empresas encontradas dificultaram sua visibilidade pública na busca de informações, tais como endereço, CNPJ; site/Facebook. Foram difíceis de encontrar, o que pode evidenciar, muitas vezes, a falta e capital e de conhecimento técnico para administrar e investir em lojas, pontos comerciais e escritórios, e também precariedade no investimento tecnológico, tendo em vista o objetivo de crescimento da marca no mercado.

Em termos de pesquisas futuras, e após o levantamento dos negócios sociais no Brasil, sugere-se uma pesquisa mais aprofundada com as 200 empresas encontradas, para a conferência detalhada das informações, assim como para a obtenção de novas informações: se a empresa possui planejamento estratégico; as dificuldades e vantagens de ter uma missão social e ambiental na sua organização; e quais foram os incentivos para o empreendedor optar por esse modelo de negócio. Também é importante promover estudos de caso com organizações congêneres, tais como Empresas do modelo Sistema B; Negócios Inclusivos; Negócios da Base da Pirâmide; Negócios Sociais e Cooperativas, de modo a alcançar uma compreensão aprofundada desse fenômeno.

De fato, são necessárias mais pesquisas que apresentem casos práticos de NS no Brasil, principalmente focadas em explanar os principais motivos de sucesso e de fracasso dessas organizações; com isso, será possível compreender melhor a forma de gestão dos NS e, por consequência, obter estudos que contribuam para a compreensão do impacto social, econômico e ambiental dessas organizações. Essas informações são cruciais para o desenvolvimento 
desse campo no Brasil, especialmente para gerar informações para os investidores que atuam nas aceleradoras, incubadoras e demais formas de alocação de recursos financeiros.

Outros esforços similares foram desenvolvidos para localizar e sistematizar os dados e informações sobre os negócios sociais no país. Contudo, em nenhum deles houve a disponibilização aberta dos negócios sociais analisados. Como desenvolver um setor em construção sem conhecer o que já vem sendo desenvolvido? Por que não tornar público algo que pode contribuir para a melhoria social e ambiental do país? É cabível um comportamento tradicional privado nas informações sobre os negócios sociais? Há outras indagações sobre a transparência de informações que merecem nossa atenção e reflexão.

Por fim, acredita-se que esta pesquisa contribui para o avanço do conhecimento empírico sobre negócios sociais, e fornece subsídios para que futuros pesquisadores fortaleçam e disseminem a temática dos NS no país. Ela também possibilitou a criação de uma plataforma aberta ao público interessado, ou seja, a utilização de banco de dados com atualizações frequentes, como fonte de informação para a realização de eventos, aproximação de empresários com investidores, e disseminação dos NS no Brasil.

\section{REFERÊNCIAS}

BARDIN, L. Análise de conteúdo. Lisboa: Edições 70, 2009.

BARKI, E. Negócios na base da pirâmide. Revista de Administração de Empresas, v. 50, n. 4, p. 448449, 2010.

BARKI, E. Negócios de impacto: tendência ou modismo? GV executivo, v. 14, n. 1, p. 14-17, 2015.

BASTOS, M. F.; VASCONCELLOS, G. M.; TEODÓSIO, A.S. S. Redes, empreendedorismo social e negócios inclusivos: em busca de um modelo compreensivo sobre inovação no combate à pobreza na América Latina. In: INTERNATIONAL SOCIETY FOR THIRD SECTOR RESEARCH CONFERENCE, 9, 2013, Santiago de Chile. Proceedings... Baltimore: ISTR, 2013, p. 1-22.
BATTILANA, J. et al. Harnessing productive tensions in hybrid organizations: The case of work integration social enterprises. Academy of Management Journal, v. 58, n. 6, p. 1658-1685, 2015.

BORZAGA, C.; DEPEDRI, S.; GALERA, G. Interpreting social enterprises. Revista de Administração, v. 47, n. 3, p. 398-409, 2012.

BOCKEN, N. M. P; FIL, A.; PRABHU, J. Scaling up social businesses in developing markets. Journal of Cleaner Production, v. 139, p. 295-308, 2016.

BUGG-LEVINE, A.; KOGUT, B.; KULATILAKA, $\mathrm{N}$. A new approach to funding social enterprises. Harvard Business Review, v. 90, n. 1/2, p. 118-123, 2012.

COMINI, G.; BARKI, E.; AGUIAR, L. T. A threepronged approach to social business: A Brazilian multi-case analysis. Revista de Administração, v. 47, n. 3, p. 385-397, 2012.

DACIN, M. T.; DACIN, P. A.; TRACEY, P. Social entrepreneurship: A critique and future directions. Organization Science, v. 22, n. 5, p. 1203-1213, 2011.

DOBSON, K. et al. Successfully creating and scaling a sustainable social enterprise model under uncertainty: The case of ViaVia Travellers Cafes. Journal of Cleaner Production, v. 172, p. 4555-4564, 2018.

DOHERTY, B; HAUGH, H.; LYON, F. Social enterprises as hybrid organizations: A review and research agenda. International Journal of Management Reviews, v. 16, n. 4, p. 417-436, 2014.

FREITAS, H. et al. O método de pesquisa survey. Revista de Administração, v. 35, n. 3, p. 105-112, 2000.

FUndAÇÃO SEADE. Perfil dos Municípios Paulistas. 2015. Disponível em: <http://www.perfil. seade.gov.br/. Acesso em 15/10/2016. 
GODÓI-DE-SOUSA, E.; FISCHER, R. M. The succession process at social enterprises in Brazil. Revista de Administração, v. 47, n. 3, p. 473-488, 2012.

GOLJA, T.; POŽEGA, S. Inclusive business-what it is all about? Managing inclusive companies. International Review of Management and Marketing, v. 2, n. 1, p. 22-42, 2012.

GRASSL, W. Business models of social enterprise: A design approach to hybridity. ACRN Journal of Social Entrepreneurship Perspectives, v. 1, n. 1, p. 37-60, 2012.

GUTIÉRREZ, R.; REFICCO, E.; TRUJILLO, D. Empresas sociales: ¿una especie en busca de reconocimiento? Revista de Administração, v. 41, n. 4, p. 404-418, 2006.

HONEYMAN, R. The B Corp Handbook: How to use business as a force for good. Oakland, CA: Berrett-Koehler Publishers, 2014.

IIZUKA, E. S. et al. Empreendedorismo social e negócios sociais: Revisão crítica e agenda de pesquisa. In: SEMINÁRIOS EM ADMINISTRAÇÃO DA UNIVERSIDADE DE SÃO PAULO (SEMEAD), 17, 2014. São Paulo. Anais... São Paulo: FEA-USP, 2014.

JÄGER, U. P.; SCHRÖER, A. Integrated organizational identity: A definition of hybrid organizations and a research agenda. VOLUNTAS: International Journal of Voluntary and Nonprofit Organizations, v. 25, n. 5, p. 1281-1306, 2014.

JAHCHAN, A. L.; COMINI, G. M.; D’AMARIO, E. Q. Negócios sociais: a percepção, a consciência e o grau de interesse pelo tema para os alunos de graduação em Administração. Administração: Ensino e Pesquisa, v. 17, n. 3, p. 537-566, 2016.

KERLIN, J. A. Defining social enterprise across different contexts: A conceptual framework based on institutional factors. In: GIDRON, B.; HASENFELD, Y. (Eds.) Social enterprises - An Organizational Perspective. London: Palgrave Macmillan, 2012. p. 91-117.
KICKUL, Jill et al. Social business education: An interview with Nobel laureate Muhammad Yunus. Academy of Management Learning \& Education, v. 11, n. 3, p. 453-462, 2012.

LOARNE-LEMAIRE, S. L.; MAALAOUI, A.; DANA, L. P. Social entrepreneurship, age and gender: toward a model of social involvement in entrepreneurship. International Journal of Entrepreneurship and Small Business, v. 31, n. 3, p. 363-381, 2017.

MATHIAS, S. L.; SAKAI, C. Utilização da ferramenta Google Forms no processo de avaliação institucional: Estudo de caso nas Faculdades Magsul, 2013. Disponível em: <http://download.inep.gov.br/ educacao_superior/avaliacao_institucional/seminarios_regionais/trabalhos_regiao/2013/centro_oeste/ eixo_1/google_forms_processo_avaliacao_instit_estudo_caso_faculdades_mag.pdf.

MÁRQUEZ, P.; REFICCO, E.; BERGER, G. Negocios inclusivos en América Latina. Harvard Business Review (edição em espanhol), p. 28-38, maio 2009. Disponível em: <https://www.researchgate.net/ profile/Ezequiel_Reficco/publication/228274326_ Inclusive_Businesses_in_Latin_America_Spanish_ Version/links/54298b240cf27e39fa8e61b7.pdf

MOZZATO, A. R.; GRZYBOVSKI, D. Análise de conteúdo como técnica de análise de dados qualitativos no campo da administração: potencial e desafios. Revista de Administração Contemporânea, v. 15, n. 4, p. 731-747, 2011.

\section{PLANO CDE. Mapeamento do campo de Negócios}

Sociais/Negócios Inclusivos. 2011. Disponível em: <https://assets.aspeninstitute.org/content/ uploads/files/content/docs/ande/Mapeamento $\% 20$ Neg\%C3\%B3cios\%20Sociais_Inclusivos\%20-\%20 Relat\%C3\%B3rio\%20final\%20categoria\%20desenvolvedores\%20e\%20investidores\%5B1\%5D.pdf>. Acesso em: 10 set. 2016.

PLESS, N. M. Social entrepreneurship in theory and practice-An introduction. Journal of Business Ethics, v. 111, n. 3, p. 317-320, 2012. 
PRAHALAD, C. K. A riqueza na base da pirâmide. Porto Alegre: Bookman, 2005.

POLAK, P.; WARWICK, M.; The business solution to poverty: designing products and services for three billion new customers. Oakland, CA: Berrett-Koehler Publishers, 2013.

ROMANI-DIAS, M. et al. Agenda de pesquisa em empreendedorismo social e negócios sociais. Revista de Administração, Contabilidade e Economia da Fundace, v. 8, n. 3, 2017.

SANTOS, T. S. et al. O artesanato como elemento impulsionador no desenvolvimento local. In: SIMPÓSIO DE EXCELÊNCIA EM GESTÃO E TECNOLOGIA (SEGeT), 7, 2010. Resende. Anais... Resende: AEDB, 2010.

SERVIÇO BRASILEIRO DE APOIO ÀS MICRO E PEQUENAS EMPRESAS. O que são negócios sociais. 2012. Disponível em: <http://www.sebrae. com.br/sites/PortalSebrae/artigos/o-que-sao-negocios-sociais $>$. Acesso em 15/10/2016.

SEVERINO, A. J. Metodologia do trabalho científico. 23. ed. São Paulo: Cortez, 2014.

SMITH, W. K.; GONIN, M.; BESHAROV, M. L. Managing social-business tensions: A review and research agenda for social enterprise. Business Ethics Quarterly, v. 23, n. 3, p. 407-442, 2013.

TEODÓSIO, A. S. S.; COMINI, G. Inclusive business and poverty: prospects in Brazilian context. Revista de Administração, v. 47, n. 3, p. 410-421, 2012.

THOMPSON, J.; DOHERTY, B. The diverse world of social enterprise: A collection of social enterprise stories. International Journal of Social Economics, v. 33, n. 5/6, p. 361-375, 2006.
TISCOSKI, G. P.; ROSOLEN, T.; COMINI, G. M. Empreendedorismo social e negócios sociais: Um estudo bibliométrico da produção nacional e internacional. In: ENCONTRO DA ASSOCIAÇÃO NACIONAL DE PÓS-GRADUAÇÃO E PESQUISA EM ADMINISTRAÇÃO, 37, 2013. Rio de Janeiro. Anais... Rio de Janeiro: ANPAD, 2013.

WRY, T.; YORK, J. G. An identity-based approach to social enterprise. Academy of Management Review, v. 42, n. 3, p. 437-460, 2017.

YUNUS, M. Credit for the poor: Poverty as distant history. Harvard International Review, v. 29, n. 3, p. 20-25, 2007.

YUNUS, M. Economic security for a world in crisis. World Policy Journal, v. 26, n. 2, p. 5-12, 2009.

YUNUS, M.; MOINGEON, B.; LEHMANN, L. Building social business models: Lessons from the Grameen experience. 2012. Disponível em: <https:// hal-hec.archives-ouvertes.fr/hal-00528385>. Acesso em: 16 set. 2014.

YUNUS, M. Negócios Sociais - Diferentes modelos de negócios. 2012. Disponível em: <http://www.yunusnegociossociais.com>. Acesso em: 16 out. 2016. 